\title{
Determinants of Technical Efficiency in Wheat Production in Ethiopia
}

\author{
Daniel Hailu \\ Department of Agricultural Economics, Ethiopian Institute of Agricultural Research (EIAR), Addis Ababa, Ethiopia
}

Email address:

danielhailu19@yahoo.com,dahagm19@gmail.com

\section{To cite this article:}

Daniel Hailu. Determinants of Technical Efficiency in Wheat Production in Ethiopia. International Journal of Agricultural Economics. Vol. 5, No. 5, 2020, pp. 218-224. doi: 10.11648/j.ijae.20200505.19

Received: August 18, 2020; Accepted: September 1, 2020; Published: October 12, 2020

\begin{abstract}
Ethiopia is the second largest wheat producing countries in Sub-Saharan Africa and most people rely on rain fed agriculture for their livelihoods. Wheat production has increased from 2,176,603 tons in 2005 to 4,219,257 tons in 2016 with $51.6 \%$ production volume increment. However, this production cannot meet the consumption demand and obliged to import wheat because of rapid population growth. This study intended to determine the technical efficiency of smallholder wheat farmers in Ethiopia. The main objective of study was to examine the effect of demographic, socioeconomic and institutional factors on technical efficiency of small holder wheat farmers in Ethiopia. The study used household level cross sectional data collected in 2015/16 cropping season from 1611 sample farmers selected by multistage sampling technique. A stochastic production frontier and two-limit Tobit regression models were used to estimate level of technical efficiency and identify factors affecting technical efficiency respectively. The study indicated that the average technical efficiency level of wheat producing farmers was $62 \%$ implying that there was technical efficiency variation among smallholder farmers in the study area. The result implied that there is an opportunity for wheat producers to increase output at existing levels of inputs with present technologies. By shifting the average farmer to the production frontier, the average yield would increase by 0.5 tons per hectare. The two-limit Tobit regression model results showed that experience of growing wheat, family size, own farm labor, livestock size, extension contact and training had positive and significant effect on technical efficiency. However, distant wheat plot have a negative and significance effect on technical efficiency level of the farmers. This suggests attention to productivity gains arising from efficient use of existing technologies is necessary. Therefore, the study suggested, policies and strategies should be directed towards increasing productivity through improving efficiency of the production process.
\end{abstract}

Keywords: Yield Gap, Efficiency, Production, Productivity, Improved Variety, Ethiopia

\section{Introduction}

Developing countries will demand food and account for about 85 percent of the 690 million ton increase in the global demand for cereals between 1995 and 2020 [1]. Empirical studies suggest that most under developed and developing countries are still facing the problem of high poverty levels. Most farmers in these countries practice subsistence farming with low productivity.

In Ethiopia most people rely on agriculture for their livelihoods. However, agricultural system in the country is primarily rain fed and the sector is still exposed to droughts and flooding. According to Federal Democratic Republic of Ethiopia [19], in Ethiopia over 7 million people still face food insecurity.
Ethiopia is the second largest wheat producing countries in sub-Saharan Africa, after South Africa [2]. For the crop year of 2015/2016, from the total land allocated for cereal crops, wheat stands in fourth by covering $13.3 \%$ of the total areas preceded by Teff, maize and sorghum.

In the last 12 years, there was a progression of wheat productivity by $61.4 \%$ and total area of production by $84 \%$. The production has increased from 2,176,603 tons in 2005 to $4,219,257$ tons in 2016 with $51.6 \%$ production volume increment.

A number of variety trials were conducted by national wheat research program in different areas of the country to address problems of different agro-ecologies production 
constraints. Accordingly, as of 2016, 76 improved wheat varieties with high-yielding potential, wide adaptation and resistance/tolerance to diseases and pests have been released [21]. However, average national productivity of wheat is 2.54 ton/hectare which is too low compared to the potential productivity of 5 ton/hectare at farmers' field [20]. This shows that production growth is largely attributed to area expansion than increased productivity.

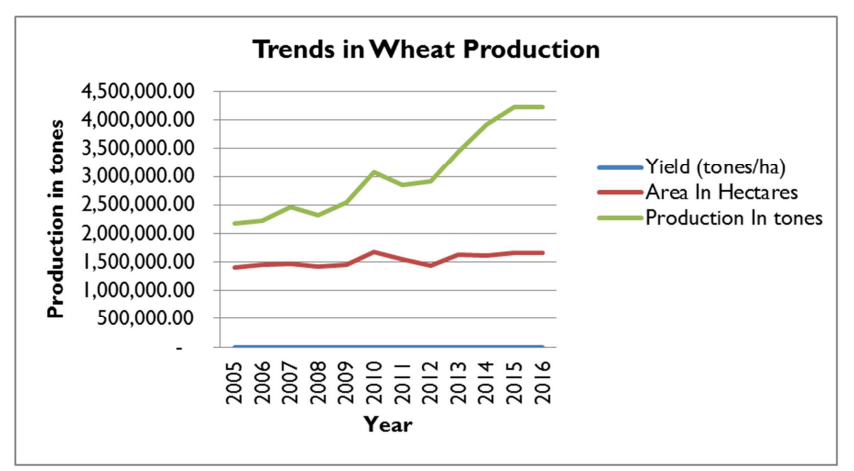

Source: own computation

Figure 1. Trends of wheat production and productivity from 2005 to 2016.

Crop yield per area (amount of crop harvested per amount of land cultivated) is the most commonly used impact indicator for agricultural productivity. Productivity can change due to differences in production technology, differences in the efficiency of the production process and differences in the environment in which production takes place. Efficiency is a very important factor of productivity growth, especially in developing agricultural economies where resources are insufficient and opportunities for developing and adopting better technologies are declining. Such economies can benefit greatly by determining the extent to which it is possible to raise productivity or increase efficiency, at the existing resource base or technology.

Several recent studies on the technical efficiency (TE) of crop production for wheat indicated the existence of a yield gap. This gap refers to the difference in productivity between best practice farms and other farms that operate with comparable available resources under similar circumstances [3].

The presence of shortfalls in efficiency indicates that output can be increased with given inputs and existing technologies. If this is the case, then empirical estimations of efficiency are important to determine the gain that could be obtained by improving the performance in production with existing technology. It also helps to find out whether the yield variability is due to random influences beyond the control of the farmers or to the factors under the control of the farms.

\section{Materials and Methods}

\subsection{The Study Area}

The study was conducted in four major wheat producing regions in Ethiopia. The regions share the larger volume in terms of producers, the area they are planted and volume of production obtained from private peasant holdings.

Table 1. Description of the study area.

\begin{tabular}{llll}
\hline & Regions & Number of holders & Area in Hectare \\
\hline & Ethiopia - All regions (2015/16) & $4,780,267$ & $1,664,564.62$ \\
1 & Amhara & $1,750,963$ & $545,106.10$ \\
2 & Oromia & $1,951,975$ & $872,252.80$ \\
3 & Tigray & 382,304 & $1,221,904.31$ \\
4 & SNNPR & 677,054 & $102,847.97$ \\
& Four regions (2015/16) & $4,762,296$ & $133,419.80$ \\
& Share & $99.6 \%$ & $1,653,626,375.14$ \\
\end{tabular}

Source: Organized by the researcher [4].

\subsection{Data Type and Sources}

Farm household survey which was collected through structured questionnaires was used for the analysis. The data was collected by Ethiopian Institute of Agricultural Research (EIAR) and the International Maize and Wheat Improvement Center (CIMMYT) during 2015/16 cropping season. Secondary data gathered from country's statistical report, crop variety register, annual reports, research papers, website, books and unpublished reports also used in the analysis..

\subsection{Sampling Techniques}

Multistage sampling procedure combining both purposive and simple random sampling was used to identity farmers to include in the sample. Sixty one districts from four regions were selected purposively from different 13 agro ecological zones based on wheat production, cultivated land and number of wheat farmers. Finally, respondents were selected in proportion with the frame by using systematic random sampling techniques from 123 peasant associations.

\subsection{Method of Data Analysis}

Descriptive and Econometric analysis were used to analyze the data. Descriptive statistics were employed to describe the demographic, socio-economic and institutional characteristics of the wheat farmers. Technical efficiency measurements are basically carried out using frontier methodologies, which shift the average response functions to the maximum output or to the efficient firm. A stochastic 
frontier model (SFM) and a two-limit Tobit regression model were employed to derive efficiency scores for the wheat producers and to determine technical inefficiency factors respectively.

\section{A stochastic frontier model (SFM)}

A Parametric Stochastic Frontier Production Function was used to assess technical efficiency of wheat producers in the study area. Following [5] and [6] the stochastic frontier production functions model will be specified as follows:

$$
Y_{i}=f\left(X_{i} ; \alpha_{i}\right)+\varepsilon_{i}
$$

Where, $Y_{i}$ is the output of farmer $i, X_{i}$ are the input variables, $\alpha_{i}$ are production coefficients and $\varepsilon$ is the error term that is composed of two elements, that is:

$$
\varepsilon_{\mathrm{i}}=\mathrm{v}_{\mathrm{i}}-\mathrm{u}_{\mathrm{i}}
$$

Where, $\mathrm{v}_{\mathrm{i}}$ represents randomness (or statistical noise) and $\mathrm{u}_{\mathrm{i}}$ represents technical inefficiency. From the error term component $\left(\mathrm{v}_{\mathrm{i}}-\mathrm{u}_{\mathrm{i}}\right), \mathrm{v}_{\mathrm{i}}$ is a two sided $(-\infty<\mathrm{v}<\infty)$ normally distributed random error $\left(\mathrm{v} \sim \mathrm{N}\left[0, \sigma^{2} \mathrm{v}\right]\right)$ that represents the stochastic effects outside the farmer's control. (example weather, natural disasters etc), measurement errors, \& other statistical noise while $U_{i}$ is a one-sided $\left(u_{i} \geq 0\right)$ efficiency component which is independent of $v_{i}$ and is normally distributed with zero mean and a constant variance $\left(\sigma^{2} \mathrm{u}\right)$ allowing the actual production fall below the frontier but without attributing all short falls in output from the frontier as inefficiency.

The technical efficiency (TE) of an individual farm is defined in terms of the ratio of the observed output $\left(\mathrm{Y}_{\mathrm{i}}\right)$ to the corresponding frontier output $\left(\mathrm{Y}_{\mathrm{i}}{ }^{*}\right)$, conditioned on the level of inputs used by the farm and mathematically expressed as:

$$
T E=\frac{Y_{i}}{Y_{i}^{*}}=\frac{E\left(Y_{i} / u_{i}, X_{i}\right)}{E\left(Y_{i} / u_{i}=0, X_{i}\right)}=e^{-\left[E\left(u_{i} / e_{i}\right)\right]}
$$

\section{A two-limit Tobit regression model}

The determinants of technical efficiency were estimated using a two-limit Tobit model with the dependent variable, as the technical efficiency indices.

Following [7] and [8], the two-limit Tobit model was defined as;

$$
Y_{i T E}^{*}=\delta_{0}+\sum_{j=1}^{n} \delta_{j} z_{i j}+u_{i}
$$

Where $\mathrm{Y}_{\mathrm{i}}{ }^{*}$ is latent variable representing the efficiency scores, $\delta_{0}, \delta_{1}, \ldots, \delta_{\mathrm{n}}$ are parameters to be estimated, and $\mathrm{TE}$ is, technical efficiency of the $\mathrm{i}^{\text {th }}$ farmer. $\mathrm{Z}_{\mathrm{i}}$ - demographic, socioeconomic and institutional factors that affect efficiency level. And $\mathrm{u}_{\mathrm{i}}$ - an error term with mean zero and variance $\delta^{2}$ $\left(\mathrm{u}_{\mathrm{i}} \sim \mathrm{IN}\left(0, \delta^{2}\right)\right)$ and farm specific efficiency scores for the smallholder wheat producers range between zero and one.

Two-limit Tobit model allows for censoring in both tails of the distribution [9]. The log likelihood that is based on the doubly censored data and built up from sets of the two - limit Tobit model is given by;

$$
\ln L=\sum_{Y_{i}=L_{o i}} \ln \varphi\left[\frac{l_{o i}-X_{i}^{\prime} \beta}{\sigma}\right]+\sum_{y_{i}=y_{i}^{*}} \ln \cdot \frac{1}{\sigma} \phi\left[\frac{Y_{i}-X_{i}^{\prime} \beta}{\sigma}\right]+\sum_{Y_{i}=l_{1 i}} \ln \left[1-\phi\left(\frac{l_{1 i-X_{i}^{\prime} \beta}}{\sigma}\right)\right]
$$

Where $\mathrm{L}_{\mathrm{oi}}=0$ (lower limit) and $\mathrm{L}_{1 \mathrm{i}}=1$ (upper limit) where $\varphi$ and $\phi$ are normal and standard density functions.

\section{The Marginal Effects}

The marginal effects of changes in explanatory variables from Tobit regression analysis were computed following the procedure proposed by [10] and later developed by [11] McDonald and Moffitt showed that a change in the independent variable $\mathrm{x}$ has three effects. The marginal effects of these conditional expectations respectively are given as:

1) The unconditional expected value of the dependent variable: The marginal effects for the unconditional expected value of the dependent variable,

$$
\frac{\partial E(y \mid \chi)}{\partial \chi}=\beta \Phi\left(\frac{\chi \beta}{\sigma}\right)
$$

2) The expected value of the dependent variable conditional upon being between the limits: The influence of explanatory variables on the expected value of the dependent variable conditional on it being larger than the lower bound.

$$
\frac{\partial E\left(y^{*} \mid \chi\right)}{\partial \chi}=\beta
$$

3) The probability of being between the limits: The influence of explanatory variables on the probability of dependent variable to fall in the uncensored part of the distribution.

$$
\frac{\partial \operatorname{Pr}(y>0 \mid \chi)}{\partial \chi}=\phi\left(\frac{\chi \beta}{\sigma}\right) \frac{\beta}{\sigma}
$$

The study explained the conditional and unconditional marginal effects of changes in explanatory variables.

\section{Results and Discussion}

\subsection{Descriptive Results}

Descriptive statistics of production function of inputs and output variables

The sample farm households realized a mean yield of 1.65 tones/ha of wheat (Table 2). However, productivity varied 
between a minimum of 0.03 tones/ha and a maximum of 6.81 tones/ha, indicating a considerable scope for improving wheat yields. The two commonly used chemical fertilizers in the production of wheat were DAP and Urea.

Table 2. Descriptive results of Input and Output.

\begin{tabular}{|c|c|c|c|c|c|}
\hline Inputs and output Variables & $\mathbf{N}$ & Minimum & Mean & Maximum & Std. Deviation \\
\hline Area in ha & 1611 & 0.01 & 0.7 & 12.5 & .7202974 \\
\hline Seed in $\mathrm{kg} / \mathrm{ha}$ & 1611 & 7 & 175.91 & $2,884.62$ & 120.5052 \\
\hline Fertilizer in $\mathrm{kg} / \mathrm{ha}$ & 1611 & 0 & 132.85 & 925 & 103.9898 \\
\hline Labor days/ha & 1611 & 1 & 59.46 & 729.17 & 74.07052 \\
\hline Oxen days/ha & 1611 & 0 & 25.35 & 224 & 14.82379 \\
\hline Output of wheat in $\mathrm{kg} / \mathrm{ha}$ & 1611 & 26.32 & $1,653.75$ & $6,814.16$ & 1034.386 \\
\hline
\end{tabular}

Source: Own Computation, 2015/16

\section{Descriptive statistics of continuous efficiency variables}

Sampled age of respondents was aged between 18 to 90 years. Most of the sampled HHHs were relatively old. Farmer's experience in wheat activities were ranged from 1 to 72 years. About $66 \%$ of the total sampled HHs had at least 6 persons in the household.

Table 3. Descriptive results continuous efficiency variables.

\begin{tabular}{lllll}
\hline Variables & N & Minimum & Mean & Maximum \\
\hline Distance to market (km) & 1611 & 0.01 & 9.1 & 42 \\
Age of household & 1611 & 18 & 45.9 & 90 \\
Labor force available & 1611 & 1 & 1.4 & 6 \\
Household size & 1611 & 1 & 6.6 & 19 \\
Farm size (Ha) & 1611 & 0.04 & 1.5 & 21.3 \\
Number of Livestock (TLU) & 1611 & 0 & 5.4 & 72 \\
Experience of growing wheat & 1611 & 1 & 3.5 & 50 \\
Extension contact & 1611 & 0 & 13.4 & 360 \\
Plot distance (Minutes) & 1611 & 0 & 3.6 & \\
\hline
\end{tabular}

Source: Own Computation, 2015/16

Descriptive statistics of discrete efficiency variables

The majority $(91.6 \%)$ of sampled respondents were male headed households. Eighty four percent of the farmers were owner-operated. While, 16 percent of the farmers were farming with contracted land (either cash rented, sharecropped, gifted or borrowed).

Table 4. Descriptive results of discrete variables.

\begin{tabular}{llll}
\hline Characteristics & Category & Frequencies & Percentages \\
\hline \multirow{2}{*}{ Sex } & Female & 136 & 8.4 \\
& Male & 1475 & 91.6 \\
\multirow{2}{*}{ Education of household } & No & 98 & 6.1 \\
& Yes & 1513 & 93.9 \\
Rely on government & No & 323 & 20 \\
support & Yes & 1288 & 80 \\
\multirow{2}{*}{ Ownership of plot } & No & 257 & 16 \\
& Yes & 1354 & 84 \\
\hline
\end{tabular}

Source: Own Computation, 2015/16

\subsection{Empirical Results}

\subsubsection{MLE of the Variance Parameters}

The maximum likelihood estimates (MLE) of the CobbDouglas based stochastic production function was specified to determine the possible relationships between the production of wheat and inputs used. The estimated values of output elasticities for all inputs are positive and significant influence on wheat output growth. Oxen power is found to have the highest elasticity, followed by plot area, labor, seed, fertilizer and chemical.

Table 5. The MLE of the Variance Parameters.

\begin{tabular}{lcll}
\hline Input Variables & coefficient & standard-error & t-ratio \\
\hline Plot Size & 0.49765446 & 0.34357930 & 0.14484413 \\
Amount of seed & 0.38775795 & 0.28673704 & 0.13523120 \\
Amount of fertilizer & 0.25387508 & 0.38354919 & 0.66191009 \\
Amount of chemicals & 0.19479395 & 0.45912556 & 0.42427163 \\
Labor days & 0.21638875 & 0.18566331 & 0.11654901 \\
Oxen days & 0.69783035 & 0.26306705 & 0.26526711 \\
sigma-squared & 0.64647112 & 0.39373086 & 0.16419113 \\
Gamma & 0.75378949 & 0.33012270 & 0.22833616 \\
log likelihood function $=-0.13865120$ & & \\
\hline
\end{tabular}

The results of MLE of variance parameters explain that variance parameter gamma $(\mathrm{Y})$ is the ratio of variance of farm specific technical efficiency to the total variance of output and has a value 0.75 which shows that out of total variation in wheat production 75 percent variation is due to technical inefficiency $u_{i}$ while remaining 25 percent is due to the uncertainty $\mathrm{v}_{\mathrm{i}}$. By shifting the average farmer to the production frontier, the average yield would increase by 0.5 tones/ha and the most technically inefficient farmer would have an efficiency gain of 0.53 tones/ha using the available resources. 


\subsubsection{Technical Efficiency Level}

The TE among the households ranges from $11 \%$ to $92 \%$, with standard deviation of 0.1493906 . The mean TE of sample households during the survey period was $62.2 \%$. The Southern region of the country scored minimum TE. The results of the efficiency scores indicate that there were wide ranges of differences in TE among wheat producing farmers.

Table 6. Technical Efficiency (TE) Levels.

\begin{tabular}{llllll}
\hline \multirow{2}{*}{ No. Regions } & \multirow{2}{*}{$\begin{array}{l}\text { No. of } \\
\text { Farmers }\end{array}$} & \multicolumn{2}{l}{ Technical Efficiency Level } \\
\cline { 5 - 6 } & & Minimum TE & Mean TE & Maximum TE \\
\hline 1 & Amhara & 509 & 0.11 & 0.58 & 0.92 \\
2 & Oromia & 837 & 0.15 & 0.65 & 0.91 \\
3 & Tigray & 84 & 0.25 & 0.67 & 0.88 \\
4 & Southern & 181 & 0.10 & 0.62 & 0.87 \\
& Ethiopia & & 0.11 & 0.62 & 0.92 \\
\hline
\end{tabular}

Source: developed by the researcher

\section{Distribution of TE Scores}

TE scores showed that the majority (more than 58\%) of the sample households had TE score between 50\%-75\% TE scores. But there were 326 households whose TE levels were below $50 \%$. Out of the total sample households, only $21 \%$ had TE greater than $75 \%$. Generally there is a considerable amount of efficiency variation among wheat producer farmers in measure of technical efficiency.

Table 7. Distribution of TE scores.

\begin{tabular}{lll}
\hline \multirow{2}{*}{ Efficiency Category } & TE & \\
\cline { 2 - 3 } & Freq. & Percentage \\
\hline $0.00 \leq \mathrm{E}<0.25$ & 26 & 1.61 \\
$0.25 \leq \mathrm{E}<0.50$ & 300 & 18.62 \\
$0.50 \leq \mathrm{E}<0.75$ & 942 & 58.47 \\
$0.75 \leq \mathrm{E}<1.00$ & 343 & 21.29 \\
Total & 1611 & 100.00 \\
\hline
\end{tabular}

Source: developed by the researcher

\subsubsection{Factors Influencing Technical Efficiency}

The results obtained from the first stage estimations indicated that the average efficiency scores were low and there existed efficiency variations among farmers. The TE estimates derived from the model were regressed on factors that explain variations in efficiency across farm households using Tobit model (Table 8).

Tobit regression model estimated to assess the determinants of technical efficiency. As shown in the table 8, among the farmer-specific characteristics, higher levels of experience in growing wheat, holding larger family size, own farm labor, holding livestock, farmers who have contacts with agricultural extension agents and those farmers received training were a positive and significant effect on technical efficiency level of the farmers. However, distant plot have a negative and significance effect on technical efficiency level of the farmers.
Table 8. Tobit Regression (determinant factors in Technical efficiency).

\begin{tabular}{lllll}
\hline Variables & Coef. (TE) & Std. Err. & t & P>|t|t \\
\hline Experience of growing & $0.0116717^{* *}$ & 0.0045518 & 2.56 & 0.010 \\
Wheat & $0.0180865^{* *}$ & 0.0091265 & 1.98 & 0.048 \\
Family size & 0.0013865 & 0.0039817 & 0.35 & 0.728 \\
Wheat plot size & $0.0221635^{* * *}$ & 0.0080781 & 2.74 & 0.006 \\
Own farm labor & -0.0011455 & 0.0009514 & -1.20 & 0.229 \\
Ownership of plot & $0.0315087 * * *$ & 0.0019150 & 16.45 & 0.000 \\
Tropical livestock unit (TLU) & $-0.0030913 * * *$ & 0.0009295 & -3.33 & 0.001 \\
Plot distance & -0.0008264 & 0.0008703 & -0.95 & 0.342 \\
Rely on government support & $0.0018939 * *$ & 0.0008334 & 2.27 & 0.023 \\
Extension contact & $0.0237985^{* * *}$ & 0.0016271 & 14.63 & 0.000 \\
Received training & & & & \\
\hline
\end{tabular}

Note: $* * *$ Significant at $1 \%, * *$ Significant at $5 \%$ and $*$ Significant at $10 \%$

The results from the Tobit model were subjected to post estimation test using marginal effect analysis in order to estimate the trivial change from each factor that influences TE. Quantification of the marginal effects of these variables is important in order to estimate the change that will occur with respect to a change in one unit of that variable.

The marginal effect analysis:

Quantification of the marginal effects of these variables is important in order to estimate the change that will occur with respect to a change in one unit of that variable (Table 9).

Table 9. The marginal effects of change in explanatory variables (TE).

\begin{tabular}{lll}
\hline \multirow{2}{*}{ Variables } & \multicolumn{2}{c}{$\mathbf{d y / d x}$} \\
\cline { 2 - 3 } & $\partial \mathbf{E}(\mathbf{y})$ & $\partial \mathbf{E}\left(\mathbf{y}^{*}\right)$ \\
\hline Experience of growing Wheat & 0.0116521 & 0.0114851 \\
Family size & 0.0180560 & 0.0177973 \\
Wheat plot size & 0.0013842 & 0.0013644 \\
Own farm labor & 0.0221261 & 0.0218091 \\
Ownership of plot & -0.0011436 & -0.0011272 \\
Tropical livestock unit (TLU) & 0.0314555 & 0.0310049 \\
Plot distance & -0.0030860 & -0.0030418 \\
Rely on government support & -0.0008250 & -0.0008132 \\
Extension contact & 0.0018907 & 0.0018636 \\
Received training & 0.0237584 & 0.0234181 \\
\hline
\end{tabular}

Experience of Growing Wheat: had a positive effect on Technical efficiency level of farmers at 5\% significant level. A unit change in the year of production experience of the household head in an increasing order would increase the probability of a farmer being technically efficient by about $1.17 \%$ and the mean level of TE by about $1.15 \%$. Results revealed that experienced farmers had the managerial capability to carry out farming activities as experience increases. The finding was consistent with [12].

Family Size: had a positive effect on Technical efficiency level of farmers at 5\% significant level. A unit change in the number of household member in an increasing order would increase the probability of a farmer being technically efficient by about $1.81 \%$ and the mean level of TE by about $1.78 \%$. Results revealed that a farmer owing larger family size can better manage the farm timely because family is the main source of labor supply. The finding was consistent with $[12,13]$. 
Own Farm Labor: had a positive effect on Technical efficiency level of farmers at $1 \%$ significant level. A unit change in spending own farm labor in the household head in an increasing order would increase the probability of a farmer being technically efficient by about $2.21 \%$ and the mean level of TE by about $2.18 \%$. Results revealed that Farms managed under hired labors may not get more energetic and active workers because of labor price competition and unable to get labor force in seasonal farming activities. Farmers who have more active family labor force enable them to allocate the required labor for different farming and production activities and become more productive. The result is in conformity with other findings of $[14,15]$.

Tropical Livestock Unit (TLU): had a positive effect on Technical efficiency level of farmers at $1 \%$ significant level. A unit change in the number of owning livestock in an increasing order would increase the probability of a farmer being technically efficient by about $3.15 \%$ and the mean level of TE by about $3.1 \%$. Results revealed that farmers who kept livestock were efficient in production. Owning livestock enables farmers to plough their plot and thresh timely, provides manure as fertilizer, source of cash to purchase input expenses and draught power. This result is similar with the study by $[12,16]$.

Plot Distance: had a negative effect on Technical efficiency level of farmers at $1 \%$ significant level. A unit change in the year of production experience of the household head in an increasing order would decrease the probability of a farmer being technically efficient by about $0.31 \%$ and the mean level of TE by about $0.3 \%$. Results revealed that distant plots require additional time to travel to farm as compared to the closer plots and made follow-up and farm management activities difficult resulting in less production and efficiency. Tadele Mamo et al. [17] found for the same.

Extension Contact: had a positive effect on Technical efficiency level of farmers at $5 \%$ significant level. A unit change in the extension contact of the household head in an increasing order would increase the probability of a farmer being technically efficient by about $0.19 \%$ and the mean level of TE by about $0.19 \%$. Results revealed that Extension workers play a central role in informing, motivating, and educating farmers about available technology in that influenced farm efficiency positively and significantly. Hunde and Abera [12] and Fekadu Gelaw and Bezabih Emana [13] found for the same.

Training: Received training had a positive effect on Technical efficiency level of farmers at $10 \%$ significant level. A unit change in number of production training received by the household head in an increasing order would increase the probability of a farmer being technically efficient by about $2.38 \%$ and the mean level of TE by about $2.34 \%$. Results revealed that training provides technical knowledge on farming and improves the ability of farmers in choosing appropriate combination of inputs to produce the maximum output. This result is similar with the study by Fekadu Gelaw and Bezabih Emana [13] and K. M.
Zahidul Islam et al. [18].

\section{Conclusion and Recommendation}

National wheat average yields are still far below attainable yields which is 2.54 tons per hectare. The yield gap of over 2.46 tons per hectare suggests that there is a potential for increasing production and productivity of smallholder wheat farmers. The results of MLE of variance parameters explain that variance parameter gamma $(\gamma)$ shows that out of total variation in wheat production 75 percent variation is due to technical inefficiency. Wheat producers in the study area are not operating at full TE level $(62 \%)$ because of level of experience in growing wheat, family size, family labor, number of livestock farmers owned, access to extension agents, training offered and distance of wheat plot. By shifting the average farmer to the production frontier, the average yield would increase by 0.5 tons per hectare which implied that there is an opportunity for wheat producers to increase output at existing levels of inputs with present technologies. Therefore, attention should be given to improve the technical efficiency level of less efficient farmers by adopting the practices of relatively more efficient farmers in the study area and yield advantage gained in national average yield. Policies and strategies of the government should give attention towards the above mentioned factors affecting technical efficiency in the study area through training and other agricultural services.

\section{References}

[1] Per Pinstrup-Andersen, Rajul Pandya-Lorch, and Mark W. Rosegrant (1999): World Food Prospects: Critical Issues for the Early Twenty-First Century. Food Policy Report. International Food Policy Research Institute Washington, D. C. October 1999.

[2] Chimdessa Uma, Yadeta Bekele, Temesgen Hirko (2017): Determinants of Technical Efficiency of Wheat Production in Ethiopia: A Review, Journal of Economics and Sustainable Development, Vol. 8, No. 19, 2017.

[3] Villano, A. R., (2005). Technical efficiency of rain fed rice farms in the Philippines: A Stochastic Frontier Production Function Approach, Working Paper, School of Economics, University of New England, Armidale, NSW, 2351.

[4] CSA (Central Statistical Agency) (2015/16): Statistical Report on Area and Crop Production, (Private Peasant Holdings, Meher Season): Addis Ababa.

[5] Khan. H and Saeed. I (2011): Measurement of Technical, Allocative and Economic Efficiency of Tomato Farms in Northern Pakistan. International Conference on Management, Economics and Social Sciences. 459-468.

[6] Bealu Tukela, Endrias Geta, and Tadesse Ababu (2013): Factors Affecting Economic Efficiency In Maize Production: The Case of Boricha Woreda In Sidama Zone, Southern Ethiopia. 28 p.

[7] Amemiya, T. (1981): Qualitative Response Models: A Survey. Journal of Economic Literature 19: 1483-1536. 
[8] Endrias Geta, Ayalneh Bogale, Belay Kassa and Eyasu Elias (2013): Productivity and Efficiency Analysis of Smallholder Maize Producers in Southern Ethiopia. 15 p.

[9] Greene, W. H., (2003): Econometric Analysis, 5th ed. Pearson Education Inc., Upper Saddle River, New Jersey. 1024 p.

[10] Mcdonald J. F. Moffitt R. A. (1980): The use of Tobit Analysis. The Review of Economics and Statistics. 62 (2): 318-321.

[11] Gould, B., W. Saup and R. Klemme (1989): Conservation tillage: the role of farm and operator characteristics and the perception of soil erosion. Land Economics, 65 (2): 167-182.

[12] Hunde K and Abera N. (2009): Technical Efficiency of Smallholder Farmers Wheat Production: The Case of Debra Libanos District, Oromia National Regional State, Ethiopia. J Agri Res 2019, 4 (5): 000232.

[13] Fekadu Gelaw and Bezabih Emana (2008): Analysis of Technical Efficiency of Wheat Production: A case study in Machakel Woreda, Ethiopia. Eth. J. of Agric. Econ. 7 (2).

[14] Alene D, Poonyth R, Hassan M (2000): Determinants of Adoption and Intensity of use of I proved Maize Varieties in the Central Highlands of Ethippia. A Tobit Analysis, Agrekon 39: 4.

[15] Hailu B (2008): Adoption of improved tef and wheat production technologies in crop-livestock mixed systems in Northern and Western Shewa Zones of Ethiopia. "PhD Thesis, Faculty of Natural and Agricultural science, University of Pretoria, Pretoria.
[16] Wudineh Getahun Tiruneh and Endrias Geta (2016): Technical efficiency of smallholder wheat farmers: The case of Welmera district, Central Oromia, Ethiopia. Journal of Development and Agricultural Economics. Vol. 8 (2), pp. 3951, February, 2016.

[17] Tadele Mamo, Wudineh Getahun, Ali Chebil, Agajie Tesfaye, Tolessa Debele, Solomon Assefa and Tesfaye Solomon (2018): Technical efficiency and yield gap of smallholder wheat producers in Ethiopia: A Stochastic Frontier Analysis. African Journal of Agricultural Research. Vol. 13 (28), pp. 1407-1418, 12 July, 2018.

[18] K. M. Zahidul Islam, Stefan Bäckman and John Sumelius (2011): Technical, Economic and Allocative Efficiency of Microfinance Borrowers and Non-Borrowers: Evidence from Peasant Farming in Bangladesh. European Journal of Social Sciences-Volume 18, Number 3 (2011).

[19] Federal Democratic Republic of Ethiopia (2011): Ethiopia's Climate-Resilient Green Economy Strategy. 14 p.

[20] Fisseha Zegeye, Bamlaku Alamirew, Degefa Tolossa, (2020): Analysis of Wheat Yield Gap and Variability in Ethiopia. International Journal of Agricultural Economics Volume 5, Issue 4, July 2020, Pages: 89-98.

[21] Ministry of Agriculture and Natural Resources (2016): Crop Variety Register. Issue No.19. June 2016. Addis Ababa, Ethiopia. 